\title{
PENGARUH TEKANAN GAS ISIAN ARGON-ETANOL DAN ARGON-BROM TERHADAP UNJUK KERJA DETEKTOR GEIGER-MUELLER
}

\author{
Sayono, BA. Tjipto Sujitno \\ PTAPB - BATAN Yogyakarta \\ Jl Babarsari Kotak Pos 6101 ykbb, Yogyakarta 55281
}

Diterima 14 Januari 2010, diterima dalam bentuk perbaikan 22 Maret 2010, disetujui 13 April 2010

\begin{abstract}
ABSTRAK
PENGARUH TEKANAN GAS ISIAN ARGON-ETANOL DAN ARGON-BROM TERHADAP UNJUK KERJA DETEKTOR GEIGER-MUELLER. Telah dilakukan penelitian pengaruh tekanan gas isian Ar-etanol dan Ar-Br terhadap unjuk kerja detektor Geiger-Mueller. Tabung detektor Geiger-Mueller terbuat dari bahan stainless steel dengan ukuran diameter tabung 1,6 cm, anoda terbuat dari bahan kawat tungsten dengan diameter 0,008 cm, panjang daerah aktif $10 \mathrm{~cm}$ dan tebal jendela yang mempunyai density thickness sekitar $0,39 \mathrm{~g} / \mathrm{cm}^{2}$. Tekanan gas isian Ar-etanol divariasi masing-masing 7:1, 9:1, dan 19:1, sedang untuk Ar-Br perbandingan tekanannya 100:1, 50:1 dan 33:1. Dari hasil pengujian terbaik diperoleh untuk perbandingan tekanan gas Ar-etanol sebesar 9:1 dihasilkan panjang plateau $180 \mathrm{~V}$, slope 9,60\%/100 V, resolving time $\tau=6,725 \mu$ detik dan tegangan operasi 1160 $\mathrm{V}$. Untuk gas Br sebagai gas pemadam dengan perbandingan tekanan 100:1 diperoleh panjang plateau $100 \mathrm{~V}$, slope $7,6 \% / 100 \mathrm{~V}$, resolving time $\tau=7,75 \mu$ detik dan tegangan operasi $540 \mathrm{~V}$. Pada penelitian ini umur detektor belum dapat diprediksi karena selama melakukan pengujian detektor masih memiliki plateau yang panjang dan bentuk pulsanya belum mengalami discharge. Jumlah cacah yang dihasilkan detektor untuk gas isian Ar-etanol sebesar $3,105 \times 10^{6}$ cacah, sedang untuk Ar-Br sebesar 1,102 × $10^{7}$ cacah.
\end{abstract}

Kata kunci : Detektor Geiger-Mueller, pemadam, plateau, slope dan resolving time

\section{ABSTRACT}

THE INFLUENCE OF ARGON-ETHANOL AND ARGON-BROMINE MAIN FILLING GAS PRESSURE ON THE PERFORMANCE OF GEIGER-MUELLER DETECTOR. It has been research on the influence of Ar-ethanol and Ar$B r$. Filled as pressure on the performance of Geiger-Mueller detector. The Geiger-Mueller detector tube is made of stainless steel with diameter of $1.6 \mathrm{~cm}$, anoda is made of tungsten wire of $0.008 \mathrm{~cm}$ in diameter, the length of active media is $10 \mathrm{~cm}$ and density thickness window $0.39 \mathrm{~g} / \mathrm{cm}^{2}$. The pressure of Ar-ethanol as filling gas were varied i.e 7:1, 9:1, and 19:1 respectively, while the ratio of pressure between $\mathrm{Ar}-\mathrm{Br}$ is 100:1; 50:1 and 33:1. The test result shows that the best result is obtained at ratio between Ar-ethanol 9:1, the length of plateau is $180 \mathrm{~V}$, slope is 9.60 $\% / 100 \mathrm{~V}$, resolving time is $6.725 \mu \mathrm{S}$ and operating voltage is $1160 \mathrm{~V}$. Meanwhile, $\mathrm{Br}$ as quenching in the ratio of $100: 1$, the length of plateau is $100 \mathrm{~V}$, the slope is $7.68 \% / 100 \mathrm{~V}$, the resolving time $7.75 \mu \mathrm{S}$ and operating voltage is $540 \mathrm{~V}$. In this research, the detector life time can not be predicted because the detector during the process of testing and still has a long plateau and the pulse shape non discharged. The number of counting resulted from the detector with Ar-ethanol as filling gas is $3.105 \times 10^{6}$ counts, while for Ar-Br is $1.102 \times 10^{7}$ counts.

Key word : Geiger-Mueller detector, quenching, plateau, slope dan resolving time

\section{PENDAHULUAN}

$D^{\prime}$

etektor nuklir merupakan instrumen bagian terdepan pada sistem instrumentasi nuklir yang berfungsi untuk mengubah besaran radiasi menjadi sinyal atau pulsa listrik, selanjutnya melalui seperangkat alat elektronik sinyal listrik dari keluaran detektor tersebut diproses menjadi informasi cacah atau pulsa listrik yang besarnya sebanding dengan intensitas atau energi radiasi yang datang ke detektor ${ }^{[1,2]}$.

Dalam perkembangannya detektor nuklir dikelompokkan menjadi 4 yakni detektor isian gas, detektor sintilasi, detektor semikonduktor dan detektor neutron. Detektor isian gas terdiri dari detektor kamar ionisasi, detektor proporsional dan detektor Geiger-Mueller. Dalam aplikasinya di lapangan detektor isian gas GeigerMueller banyak digunakan, misalnya untuk surveymeter, monitoring lingkungan, mengetahui kebocoran pada pengelasan tangki minyak, mengukur ketebalan bahan dan lain-lain ${ }^{[2]}$.

Prinsip kerja detektor Geiger-Mueller adalah memanfaatkan adanya proses ionisasi sekunder yang berasal dari ionisasi primer akibat interaksi zarah radiasi dengan medium gas isian detektor setelah diberi beda 
potensial tertentu. Adanya beda potensial pada anoda dan katoda akan menimbulkan medan listrik, akibatnya pasangan ion-elektron mendapat tambahan energi kinetik sehingga dalam perjalanannya menuju elektroda (ion menuju katoda dan elektron ke arah anoda) dapat mengionisasi gas isian sehingga terjadi pasangan ion-elektron sekunder dan bila ion-elektron sekunder masih kelebihan energi akan menumbuk gas isian lagi yang menyebabkan ionisasi tersier dan seterusnya, dan akhirnya akan terjadi jumlah pasang ion-elektron yang banyak sekali atau sering disebut peristiwa avalanche. Pengumpulan elektron pada anoda selanjutnya dikeluarkan melewati tahanan sehingga timbul denyut atau pulsa listrik yang besarnya sebanding dengan intensitas radiasi yang datang ${ }^{[3]}$.

Penelitian tentang pembuatan detektor Geiger-Mueller telah dimulai pada dekade delapan puluhan di PPBMl yang sekarang bernama PTAPB-BATAN, pada saat itu tabung detektor yang berfungsi sebagai katoda dibuat dari tabung gelas yang bagian dalamnya dilapisi dengan tembaga dengan teknik evaporasi/penguapan sedang anoda dibuat dari kawat tungsten. Detektor Geiger-Mueller yang telah dibuat mempunyai spesifikasi teknis mekanik diameter tabung $1,6 \mathrm{~cm}$, diameter anoda $0,008 \mathrm{~cm}$ dan panjang daerah aktif $10 \mathrm{~cm}$, dengan gas isian argon (Ar)-etanol. Dari hasil pengujian karakteristik detektor diperoleh panjang daerah tegangan kerja (plateau) 100-150 volt, slope 10-20\%/100 volt, tegangan operasi 1100-1300 volt, waktu yang diperlukan oleh detektor untuk dapat mencacah radiasi yang datang berikutnya (resolving time) dalam orde ratusan mikro detik dan umur detektor sekitar $10^{6} \mathrm{cacah}^{[2,4]}$.

Permasalahan yang selalu muncul dalam membuat detektor nuklir Geiger-Mueller selama ini adalah plateau, slope dan tegangan operasi cepat berubah menjadi lebih tinggi sehingga umur detektor menjadi pendek. Kelemahan ini tentunya merupakan tantangan yang harus dicari solusinya. Tegangan operasi yang cepat berubah menjadi lebih tinggi dimungkinkan karena pemilihan jenis gas yang digunakan dan perbandingan antara tekanan gas isian detektor yang kurang tepat, umur detektor pendek dimungkinkan karena adanya kebocoran gas isian melalui sambungan pada anoda maupun katoda karena sistem pengelasan antara gelas dan logam yang kurang baik. Berdasarkan pada permasalahan tersebut, maka dilakukan penelitian dengan judul Pengaruh Tekanan Gas Isian Argon-Etanol (Ar-etanol) dan Argon-Brom (Ar-Br) Terhadap Unjuk Kerja Detektor GeigerMueller

Tujuan penelitian adalah diperoleh perbandingan tekanan gas isian yang tepat untuk Ar-etanol dan $\mathrm{Ar}-\mathrm{Br}$ sehingga dihasilkan unjuk kerja pada detektor Geiger-Mueller yang terbaik yakni diperoleh panjang plateau $\geq 100$ volt, slope $\leq 10 \% / 100$ volt dan tegangan operasi 1000-1250 volt untuk gas isian Ar-etanol dan 600-850 volt untuk Ar-Br ${ }^{[5]}$.

Ruang lingkup penelitian meliputi pembuatan tabung detektor, pengisian gas isian gas Ar-ethanol dan Arbrom dan pengujian karakteristik detektor yang meliputi panjang plateau, slope, tegangan operasi, resolving time, faktor koreksi dan umur detektor.

Manfaat dari penelitian ini adalah dapat dikuasainya teknologi pembuatan detektor nuklir khususnya detektor Geiger-Mueller dan karakterisasinya sehingga dapat meningkatkan kemampuan Sumber Daya Manusia (SDM) dan dapat menjadi acuan untuk penelitian berikutnya serta dapat menunjang kegiatan penelitian dan pengembangan di bidang iptek nuklir.

\section{DASAR TEORI}

\section{Detektor Isian Gas}

Detektor isian gas merupakan tabung tertutup yang berisi gas dan terdiri dari 2 buah elektroda. Dinding tabung sebagai elektroda negatif (katoda) dan kawat yang terbentang di dalam tabung pada poros sebagai elektroda positif (anoda). Skema detektor isian gas disajikan pada Gambar 1.

Detektor isian gas prinsip kerjanya memanfaatkan terjadinya ionisasi gas isian pada medium aktif dalam detektor akibat adanya interaksi dengan zarah radiasi maka akan timbul pasangan ion-elektron. Dengan adanya beda potensial pada anoda dan katoda maka akan timbul medan listrik, sehingga pasangan ion-elektron akan terpisahkan. Ion akan bergerak ke arah katoda dan elektron bergerak ke anoda.

Telah dijelaskan sebelumnya bahwa detektor Geiger-Mueller merupakan salah satu jenis detektor isian gas yang bekerjanya memanfaatkan ionisasi sekunder yang berasal dari ionisasi primer akibat interaksi radiasi dengan medium gas isian detektor. Oleh karena kedua elektroda diberi beda potensial maka akan timbul medan listrik, akibatnya pasangan ion-elektron mendapat tambahan energi kinetik sehingga dalam perjalanannya 
Pengaruh Tekanan Gas Isian Argon-Etanol dan Argon-Brom Terhadap Unjuk Kerja Detektor Geiger-Mueller (Sayono, BA. Tjipto Sujitno)

menuju elektroda (ion menuju katoda dan elektron ke arah anoda) dapat mengionisasi gas isian sehingga terjadi pasangan ion-elektron sekunder. Skema prinsip kerja detektor Geiger-Mueller dan proses ionisasi sekunder disajikan pada Gambar 2 dan Gambar 3.

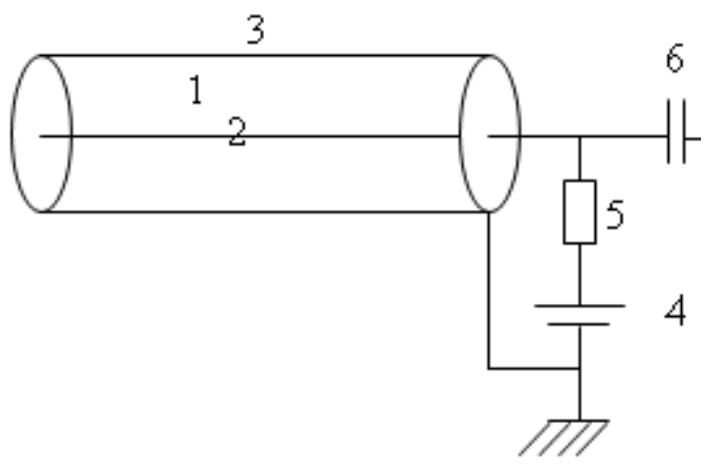

Keterangan

1. Medium aktif detektor,

2. Anoda,

3. Katoda,

4. Sumber tegangan tinggi,

5. Resistor,

6. Kapasitor.

Gambar 1. Skema detektor isian gas ${ }^{[6]}$.

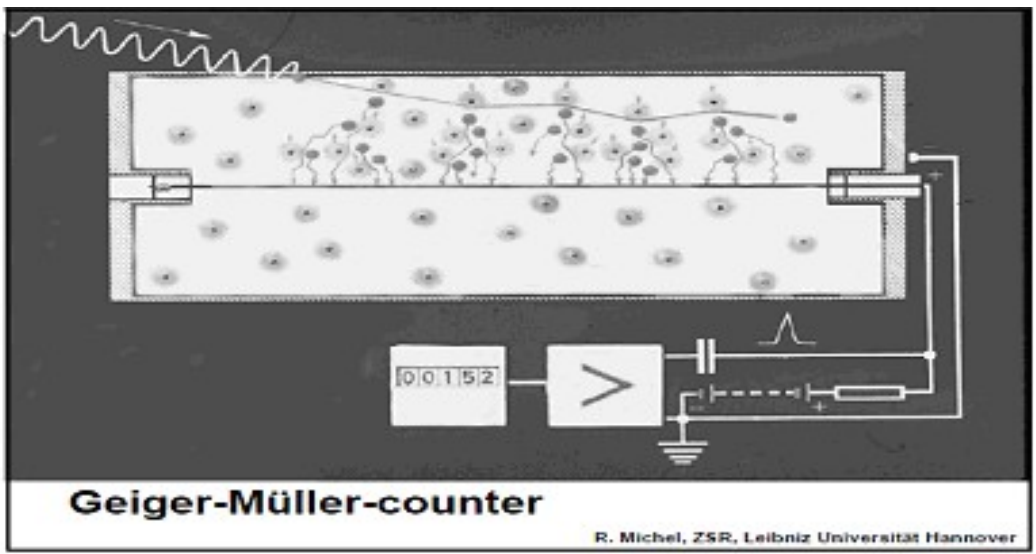

Gambar 2. Skema prinsip kerja detektor Geiger-Mueller ${ }^{[7]}$.

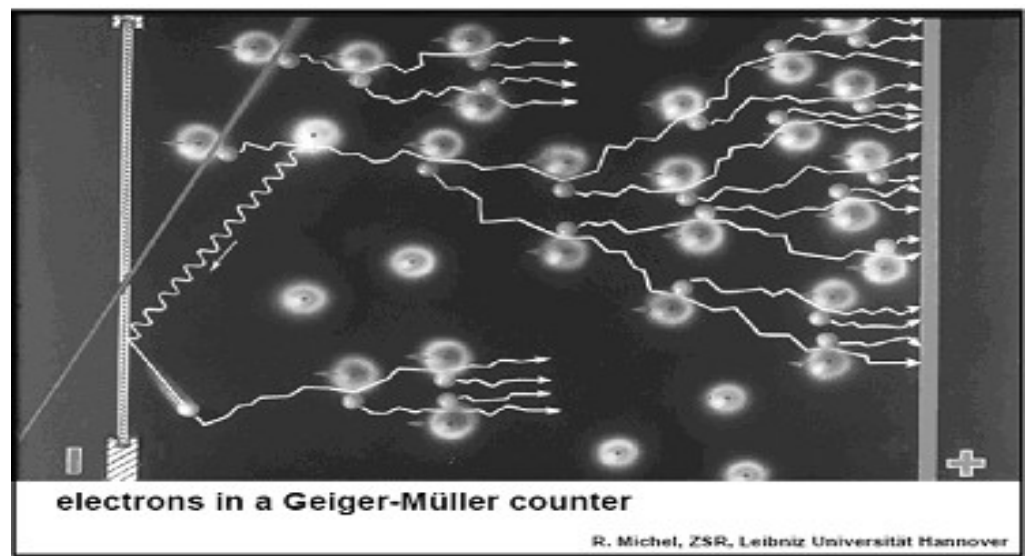

Gambar 3. Proses ionisasi sekunder di dalam tabung detektor Geiger-Mueller ${ }^{[7]}$.

Pada tegangan tertentu peristiwa terjadinya avalanche tidak tergantung lagi oleh jenis dan energi radiasi yang datang, namun masih sebanding dengan intensitas radiasi yang datang, sehingga pulsa-pulsa listrik yang terjadi amplitudonya tidak tergantung oleh energi radiasi, tinggi amplitudo pulsa sama besar, hanya kuantitasnya 
yang sebanding dengan intensitas radiasi yang datang. Detektor yang bekerja pada daerah tegangan ini disebut detektor Geiger-Mueller. Pulsa keluaran dari detektor Geiger-Mueller tinggi pulsa/amplitudonya tidak tergantung lagi dengan jenis dan energi radiasi yang datang, sehingga detektor Geiger-Mueller tidak dapat digunakan untuk spektroskopi nuklir ${ }^{[3]}$.

Dengan adanya beda potensial antara anoda dan katoda, maka timbul medan listrik yang dapat memisahkan pasangan ion dan elektron yang terbentuk. Ion positif bergerak ke arah katoda dan elektron bergerak ke arah anoda. Kecepatan gerak (v) ion dan elektron dinyatakan sebagai fungsi linear.

Untuk bentuk silinder diformulasikan ${ }^{[8]}$

$$
v=\frac{\mu}{P} \times \frac{V}{r \ln \frac{b}{a}}
$$

dengan $v$ : kecepatan gerak ion ( $\mathrm{cm} /$ detik),

$V$ : tegangan antara anoda dengan katoda (volt),

$b$ : jari-jari katoda $(\mathrm{cm})$,

a : jari-jari anoda $(\mathrm{cm})$,

$r$ : jari-jari tabung dari pusat ke ujung antara anoda dan katoda $(\mathrm{cm})$,

$\mu$ : mobilitas $\left(\mathrm{cm} /\right.$ detik) $(\text { volt } / \mathrm{cm})^{-1}(\mathrm{cmHg})$,

$P$ : tekanan gas isian.

\section{Medan Listrik di Dalam Tabung Detektor}

Tabung detektor yang digunakan untuk silinder yang berporos konsentris. Jari-jari tabung bagian luarnya (katoda) adalah b dan jari-jari kawat yang terbentang di bagian dalam (anoda) adalah a. Dengan $r$ adalah jari-jari mulai dari pusat tabung ke antara ujung a dan b. Untuk lebih jelasnya disajikan pada Gambar 4

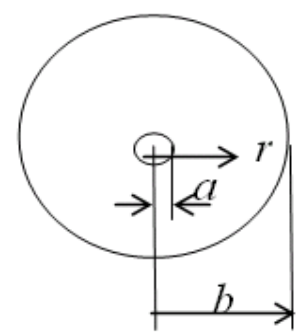

Gambar 4. Jari-jari tabung (r) dari pusat tabung ke antara ujung anoda dan katoda ${ }^{[8]}$.

Untuk detektor yang berbentuk silinder dengan pusat muatan adalah poros dan jari-jari $r$ serta beda potensial sebesar $\mathrm{V}$ pada jarak $\mathrm{r}$, maka garis gaya yang menembus seluruh selimut silinder akan berbanding lurus dengan kuat medan listriknya $\mathrm{E}_{(r)}$ dinyatakan dalam persamaan sebagai ${ }^{[8,9]}$

$$
E_{(r)}=\frac{V_{(r)}}{r \ln \frac{b}{a}}
$$

\section{TATA KERJA PENELITIAN}

\section{Pembuatan Tabung Detektor Geiger-Mueller}

Pembuatan tabung detektor dari bahan stainless steel dan tutup dari tabung gelas dikerjakan dengan menggunakan mesin bubut yang ada di fasilitas Bengkel Elektro Mekanik (BEM) PTAPB-BATAN Yogyakarta, sedang anoda detektor dibuat dari bahan kawat tungsten dengan diameter 0,08 $\mathrm{mm}$. Tabung detektor GeigerMueller dari logam dan detail komponen tabung detektor disajikan pada Gambar 5. 
Bahan-bahan detektor Geiger-Mueller yang telah selesai dikerjakan dicuci menggunakan ultrasonic cleaner dengan detergen untuk menghilangkan minyak, kemudian dibilas dengan aquades dan terakhir digunakan alkohol kemudian dikeringkan dan disimpan pada ruang vakum (desikator).

Setelah semua komponen detektor dalam kondisi bersih, maka dilakukan perakitan dengan cara memasang tutup menggunakan lem epoxy super strength.pada kedua ujung tabung detektor, sedang pemasangan anoda dari bahan kawat tungsten yang dipasang tepat pada poros sumbu tabung detektor dilakukan dengan teknik pengelasan gelas logam antara kawat tungsten dan tutup gelas pada kedua ujung tabung detektor ${ }^{[10]}$. Hasil perakitan detektor Geiger-Mueller disajikan pada Gambar 6.

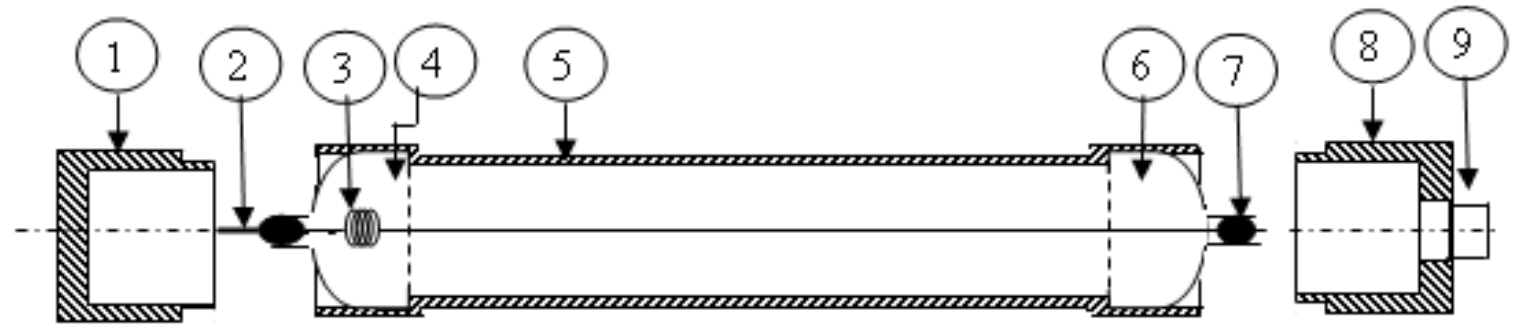

Gambar 5. Tabung detektor Geiger-Mueller dari tabung logam (stainless steel).

Keterangan: 1. Tutup luar detektor sebelah kiri

2. Anoda

3. Pir/ pegas

4. Tutup detektor sebelah kiri

5. Tabung detektor
6. Tutup tabung detektor sebelah kanan

7. Sambungan gelas dengan logam (dilas)

8. Tutup detektor luar sebelah kanan

9. Terminal keluaran (BNC)

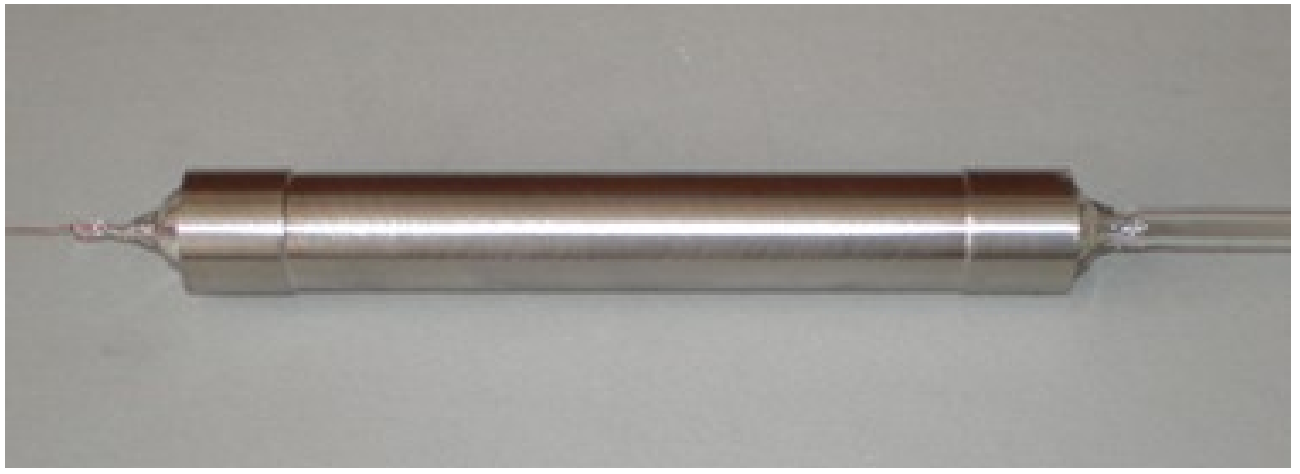

Gambar 6. Hasil perakitan tabung detektor Geiger-Mueller.

\section{Pemvakuman Tabung Dan Pengisian Gas Detektor}

Tabung detektor yang telah dirakit selanjutnya dilakukan pemvakuman menggunakan pompa rotari hingga tekanan $10^{-2}$ torr kemudian dilanjutkan dengan pompa difusi agar diperoleh keampaan sekitar $2 \times 10^{-5}$ torr. Tabung detektor yang telah mencapai kevakuman tinggi, siap diisi gas.

Dalam pengisian gas pada detektor, gas etanol dan brom sebagai pemadam yang mempunyai tekanan lebih rendah yakni $1 \mathrm{cmHg}$ dan $0,2 \mathrm{cmHg}$ dimasukkan terlebih dahulu ke dalam tabung detektor kemudian diikuti gas argon sebagai gas utama yang mempunyai tekanan lebih tinggi sebesar $7 \mathrm{cmHg}$ kemudian tabung detektor yang lain perbandingan tekanan Ar-etanol divariasi sebesar 9:1, dan 19:1 untuk gas Ar-etanol. Dengan cara yang sama dilakukan untuk detektor yang diisi dengan gas argon dan brom pada perbandingan tekanan 100:1, 50:1 dan 33:1. Bila tekanan gas yang lebih tinggi dimasukkan ke tabung terlebih dahulu maka akan kesulitan untuk memasukan gas pemadam yang tekanannya lebih rendah karena adanya gaya tolak dari gas yang ada di dalam tabung sehingga campuran gas kurang homogen. Skema sistem instalasi pemvakuman dan pengisian gas detektor Geiger-Mueller disajikan pada Gambar 7.

\section{Pengujian Karakteristik Detektor Geiger-Mueller}


Pengujian detektor dilakukan untuk mengetahui karakteristik yang meliputi panjang daerah tegangan kerja (plateau), slope, tegangan operasi, resolving time dan umur detektor. Hal ini dilakukan untuk mengetahui kualitas detektor dan respon terhadap radiasi maupun tanpa radiasi (cacah latar). Susunan rangkaian alat uji detektor Geiger-Mueller disajikan pada Gambar 8.

Untuk mengetahui panjang daerah tegangan kerja (plateau), slope, tegangan operasi detektor dari hasil variasi tekanan gas isian, maka untuk setiap perlakukan variasi gas isian dilakukan pencacahan terhadap perubahan tegangan operasi detektor. Data hasil pencacahan detektor dengan gas isian Ar-etanol.menggunakan suber radiasi Cs-137 ditunjukkan pada Tabel 1 sedang data hasil pencacahan detektor dengan gas isian $\mathrm{Ar}-\mathrm{Br}$ menggunakan sumber radiasi Cs-137 disajikan pada Tabel 2.

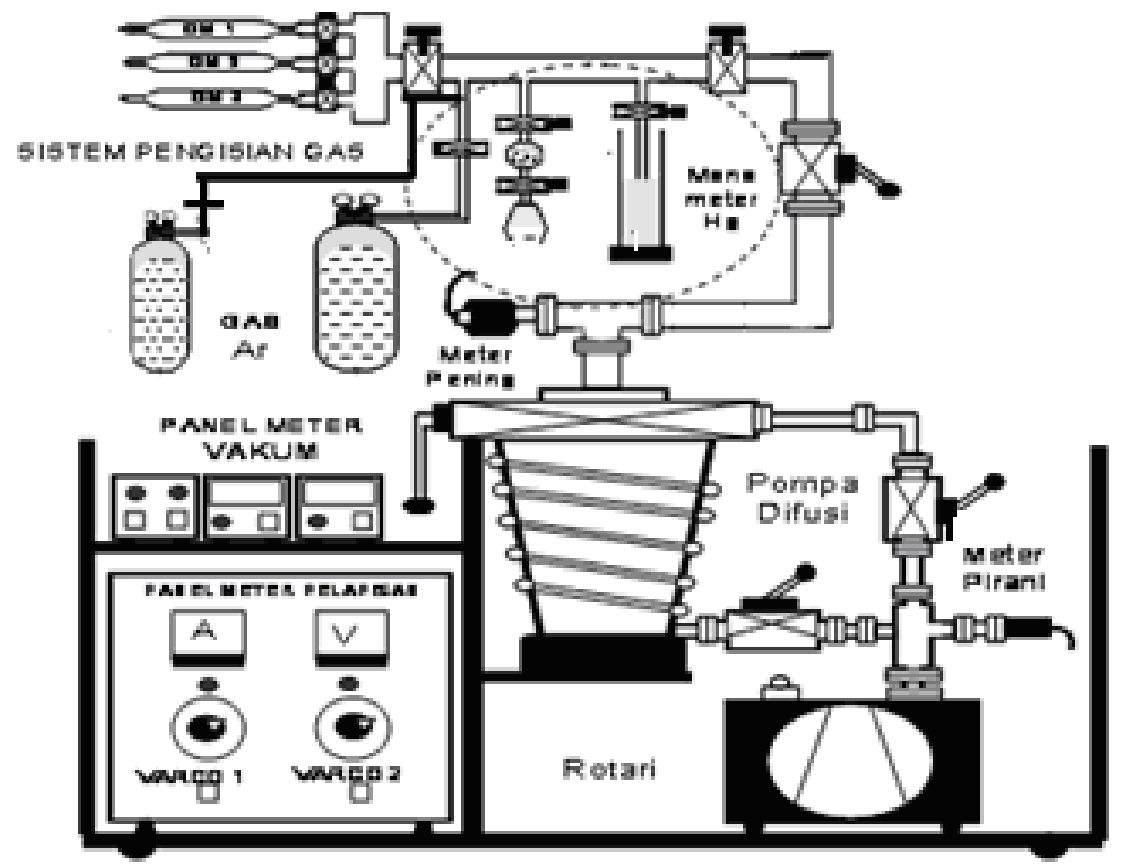

Gambar 7. Skema sistem instalasi pemvakuman dan pengisian gas detektor Geiger-Mueller.

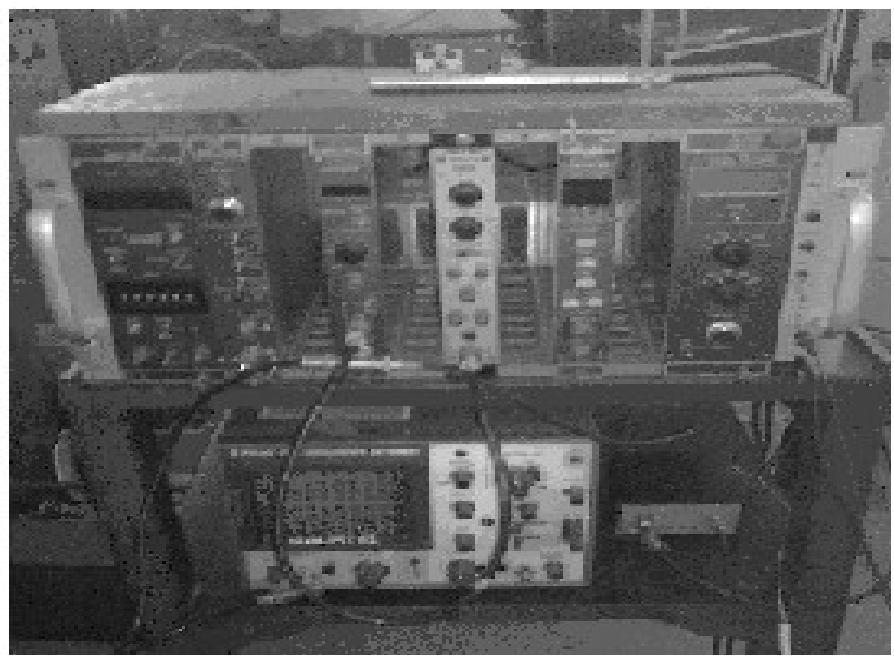

Gambar 8. Skema rangkaian alat uji detektor Geiger-Mueller

HASIL DAN PEMBAHASAN 
Pengaruh Tekanan Gas Isian Argon-Etanol dan Argon-Brom Terhadap Unjuk Kerja Detektor Geiger-Mueller (Sayono, BA. Tjipto Sujitno)

Pengujian Plateau, Slope dan Tegangan Operasi Detektor Geiger-Mueller Dengan Isian Gas Ar-Etanol dan $\mathrm{Ar}-\mathrm{Br}$

Data untuk menentukan plateau, slope dan tegangan operasi dari variasi tekanan $\mathrm{Ar}$-etanol dan $\mathrm{Ar}-\mathrm{Br}$ disajikan pada Tabel 1 dan Tabel 2.

Tabel 1. Data hasil pencacahan detektor dengan gas isian Ar-etanol.menggunakan sumber radiasi Cs-137

\begin{tabular}{|c|c|c|c|}
\hline \multirow{2}{*}{$\begin{array}{c}\text { Tegangan } \\
\text { tinggi }(\mathrm{V})\end{array}$} & \multicolumn{3}{|c|}{$\begin{array}{c}\text { Perbandingan tekanan gas isian Ar:etanol } \\
\text { dengan tekanan total } 10 \mathrm{cmHg}\end{array}$} \\
\hline & $7: 1$ & $9: 1$ & $19: 1$ \\
\hline 980 & $80 \pm 4$ & & \\
\hline 1000 & $95 \pm 3$ & & \\
\hline 1020 & $219 \pm 4$ & & \\
\hline 1040 & $2985 \pm 3$ & $60 \pm 3$ & \\
\hline 1060 & $3118 \pm 5$ & $112 \pm 2$ & \\
\hline 1080 & $3227 \pm 5$ & $3026 \pm 37$ & \\
\hline 1100 & $3331 \pm 5$ & $3062 \pm 46$ & $2117 \pm 36$ \\
\hline 1120 & $3426 \pm 18$ & $3148 \pm 44$ & $3093 \pm 53$ \\
\hline 1140 & $3506 \pm 36$ & $3190 \pm 47$ & $3106 \pm 49$ \\
\hline 1160 & $3623 \pm 57$ & $3210 \pm 45$ & $3301 \pm 50$ \\
\hline 1180 & $4223 \pm 47$ & $3234 \pm 46$ & $3532 \pm 42$ \\
\hline 1200 & $5274 \pm 39$ & $3264 \pm 46$ & $3579 \pm 67$ \\
\hline 1220 & & $3349 \pm 44$ & $5443 \pm 74$ \\
\hline 1240 & & $3501 \pm 43$ & $7183 \pm 59$ \\
\hline 1260 & & $3527 \pm 41$ & \\
\hline 1280 & & $4547 \pm 56$ & $6397 \pm 73$ \\
\hline 1300 & & & \\
\hline
\end{tabular}

Tabel 2. Data hasil pencacahan detektor dengan gas isian $\mathrm{Ar}-\mathrm{Br}$, menggunakan sumber radiasi Cs-137 


\begin{tabular}{|c|c|c|c|}
\hline \multirow{2}{*}{$\begin{array}{c}\text { Tegangan tinggi } \\
(V)\end{array}$} & \multicolumn{3}{|c|}{$\begin{array}{c}\text { Perbandingan tekanan gas isian } \mathrm{Ar}: \mathrm{Br} \\
\text { dengan tekanan total } 20 \mathrm{cmHg}\end{array}$} \\
\hline & $100: 1$ & $50: 1$ & $33: 1$ \\
\hline 470 & $809 \pm 8$ & & \\
\hline 490 & $2047 \pm 33$ & & \\
\hline 510 & $2055 \pm 41$ & & \\
\hline 530 & $1985 \pm 35$ & & \\
\hline 550 & $2082 \pm 14$ & & \\
\hline 570 & $2169 \pm 13$ & & \\
\hline 590 & $2208 \pm 53$ & $142 \pm 3$ & \\
\hline 610 & $2560 \pm 16$ & $1451 \pm 41$ & $127 \pm 18$ \\
\hline 630 & $2791 \pm 74$ & $1648 \pm 8$ & $1025 \pm 6$ \\
\hline 650 & & $1724 \pm 7$ & $1034 \pm 16$ \\
\hline 670 & & $1790 \pm 16$ & $1200 \pm 38$ \\
\hline 690 & & $1948 \pm 32$ & $1379 \pm 21$ \\
\hline 710 & & $2436 \pm 43$ & $1491 \pm 49$ \\
\hline 730 & & $3304 \pm 49$ & $2316 \pm 46$ \\
\hline 750 & & $5219 \pm 65$ & \\
\hline 770 & & & \\
\hline 790 & & & \\
\hline 810 & & & \\
\hline
\end{tabular}




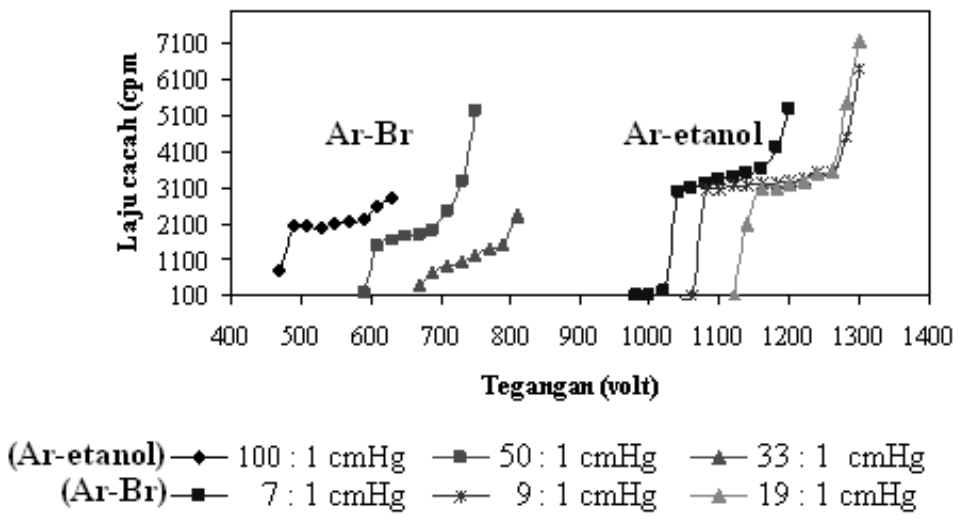

Gambar 9. Hubungan tegangan terhadap laju cacah.

Dari Tabel 1 dan Tabel 2, selanjutnya dibuat grafik hubungan tegangan terhadap laju cacah yang disajikan pada Gambar 9. Berdasarkan Gambar 9 dan Tabel 1 maka panjang plateau dari detektor dapat dihitung menggunakan persamaan panjang plateau $=V_{2}-V_{1}$. Untuk perbandingan gas Ar-etanol sebesar 7:1 pada tekanan total $10 \mathrm{cmHg}$ diperoleh panjang plateau $=V_{2}-V_{1}=1160-1040 \mathrm{~V}=120 \mathrm{~V}$

Tegangan operasi detektor Geiger-Mueller dapat ditentukan dengan cara setengah (1/2) dari panjang plateau $^{[3]}$ dan dirumuskan $=\frac{V_{1}+V_{2}}{2}$, dengan $\mathrm{V}_{1}$ : tegangan ambang (threshold voltage), $\mathrm{V}_{2}$ : tegangan ambang mulai lucutan (break down discharge).

Berdasarkan Tabel 1, tegangan operasi detektor diperoleh $=\frac{(1160+1040)}{2} \mathrm{~V}=1100 \mathrm{~V}$

Slope dihitung menggunakan persamaan ${ }^{[3]}=\frac{100\left(N_{2}-N_{1}\right) / N_{1}}{V_{2}-V_{1}} \times 100 \%$,

dengan $\quad V_{1}$ : tegangan ambang (threshold voltage),

$V_{2}$ : tegangan ambang mulai lucutan (break down discharge),

$\mathrm{N}_{1}$ : jumlah cacah pada tegangan $\mathrm{V}_{1}$,

$\mathrm{N}_{2}$ : jumlah cacah pada tegangan $\mathrm{V}_{2}$

Slope untuk perbandingan gas Ar-etanol sebesar 7:1 berdasarkan Tabel 1 diperoleh

$$
\begin{aligned}
\text { Slope } & =\frac{100\left(N_{2}-N_{1}\right) / N_{1}}{V_{2}-V_{1}} \times 100 \% \\
& =\frac{100(3611-2984) / 2984}{1160-1040} \times 100 \%=18,12 \% / 100 \mathrm{~V} .
\end{aligned}
$$

Dengan cara perhitungan yang sama, maka plateau, slope dan tegangan operasi untuk perbandingan gas Ar-etanol (7:1; 9:1 dan 19:1) dan $\mathrm{Ar}-\mathrm{Br}(100: 1 ; 50: 1$ dan 33:1 dapat ditentukan, dan hasil perhitungannya disajikan pada Tabel 3.

Berdasarkan Tabel 3, maka tegangan operasi detektor Geiger-Mueller untuk gas isian Ar-etanol dengan tekanan divariasi masing-masing 7:1;9:1 dan 19:1 diperoleh tegangan operasi berturut-turut $1100 \mathrm{~V}, 1160 \mathrm{~V}$ dan 1200 V. Hasil ini menunjukkan bahwa dari ketiga variasi perbandingan tekanan gas isian detektor Geiger-Mueller (Ar-etanol), tekanan gas pemadam (etanol) mempunyai pengaruh terhadap tegangan operasi detektor, semakin kecil tekanan gas pemadam maka akan menghasilkan tegangan operasi yang semakin tinggi. Hal ini karena semakin kecil tekanan gas pemadam berarti dalam tabung detektor didominasi oleh gas Ar yang mempunyai potensial ionisasi $15,7 \mathrm{eV}$ lebih besar dari uap etanol sebesar 12,7 $\mathrm{eV}^{[8]}$ sehingga untuk menghasilkan proses ionisasi agar terjadi pasangan ion-elektron diperlukan tegangan yang semakin tinggi. 
Tabel 3. Hasil perhitungan panjang plateau, slope dan tegangan operasi untuk gas isian $\mathrm{Ar}$-etanol dan $\mathrm{Ar}-\mathrm{Br}$

\begin{tabular}{|l|c|l|l|}
\hline Perbandingan gas isian & Panjang plateau (V) & Slope(\%/100 V) & Tegangan operasi (V) \\
\hline Gas isian Ar-etanol, dengan tekanan total $10 \mathrm{cmHg}$ \\
\hline $7: 1$ & 120 & 17,51 & 1100 \\
\hline $9: 1$ & 180 & 9,60 & 1160 \\
\hline $19: 1$ & 100 & 20,58 & 1200 \\
\hline Gas isian Ar-Br, dengan tekanan total $20 \mathrm{cmHg}$ \\
\hline $100: 1$ & 100 & 7,68 & 540 \\
\hline $50: 1$ & 80 & 42,32 & 650 \\
\hline $33: 1$ & 70 & 67,20 & 750 \\
\hline
\end{tabular}

Dari hasil pentuan panjang plateau (daerah tegangan kerja) dan perhitungan slope (kemiringan daerah tegangan kerja) sebagaimana disajikan pada Tabel 3 dari variasi perbandingan tekanan gas Ar-etanol masingmasing 7:1, 9:1 dan 19:1 dengan tekanan total $10 \mathrm{cmHg}$, berturut-turut diperoleh panjang plateau dan slope 120 $\mathrm{V}$ dengan slope17,51 \%/100 V, $180 \mathrm{~V}$ dengan slope 9,60 \%/100 V dan $100 \mathrm{~V}$ dengan slope 20,58 \%/100 V. Dengan hasil ini, maka detektor yang dibuat telah mempunyai kualitas plateau yang cukup baik karena mempunyai panjang plateau $\geq 100 \mathrm{~V}$, sedang slope untuk perbandingan tekanan gas Ar-etanol 7:1 dan 19:1 diperoleh slope sebesar 17,51 \%/100 V dan 20,58 \%/100 V. Hasil ini kurang baik, karena masih di atas 10\%/100 volt, menurut HARSHAW [11] kualitas detektor Geiger-Mueller dikatakan baik jika mempunyai panjang plateau? $100 \mathrm{~V}$ dengan slope $\leq 10 \% / 100 \mathrm{~V}$. Hasil ini juga membuktikan bahwa tekanan gas etanol yang terlalu tinggi dan terlalu rendah sangat berpengaruh terhadap plataeu dan slope detektor sehingga perlu dicari kondisi yang optimum, dalam hal ini diperoleh pada perbandingan 9:1 untuk gas Ar dan etanol dengan menghasilkan panjang plateau, slope dan tegangan operasi terbaik sebesar $180 \mathrm{~V}$ dengan slope 9,60\%/100 V pada tegangan operasi $1160 \mathrm{~V}$.

Untuk detektor Geiger-Mueller yang menggunakan gas isian $\mathrm{Ar}-\mathrm{Br}$ sebagaimana ditunjukkan pada Tabel 3 untuk variasi perbandingan tekanan 100:1, 50:1, dan 33:1 dengan tekanan total $10 \mathrm{cmHg}$, berturut-turut diperoleh panjang plateau, slope dan tegangan operasi $100 \mathrm{~V}$, slope 7,68\%/100 V pada tegangan operasi $540 \mathrm{~V}, 80 \mathrm{~V}$, slope 42,32\%/100 V pada tegangan operasi $650 \mathrm{~V}$ dan $70 \mathrm{~V}$, slope $67,20 \% / 100 \mathrm{~V}$ pada tegangan $750 \mathrm{~V}$.

Dari ketiga variasi perbandingan tekanan tersebut diperoleh hasil terbaik pada perbandingan 100:1 $\mathrm{cmHg}$ untuk $\mathrm{Ar}-\mathrm{Br}$ dengan hasil panjang plateau $100 \mathrm{~V}$, slope sebesar 7,68 \%/100 V pada tegangan operasi $540 \mathrm{~V}$. Hasil ini menunjukkan bahwa tekanan gas $\mathrm{Br}$ yang semakin rendah akan menghasilkan karakteristik detektor yang lebih baik yakni mempunyai panjang plateau $100 \mathrm{~V}$ dan slope $<10 \% / 100 \mathrm{~V}$ dan tegangan operasi di bawah 800 V. Ini sesuai dengan pendapat PRICE. W.J dan HARSHAW ${ }^{[8,11]}$ yang menyatakan bahwa detektor GeigerMueller yang menggunakan gas halogen $(\mathrm{Br}, \mathrm{Cl})$ sebagai gas pemadam dapat menghasilkan tegangan operasi sekitar 600-850 volt. Hal ini terjadi karena gas $\mathrm{Br}$ sebagai gas pemadam mempunyai potensial ionisasi rendah $12,7 \mathrm{eV}$ dan sifatnya sangat reaktif sehingga mudah terionisasi, dengan demikian untuk menghasilkan proses ionisasi cukup dengan tegangan yang rendah.

Ini merupakan keuntungan karena detektor Geiger-Mueller dalam operasinya hanya membutuhkan konsumsi catu daya rendah bila dibanding dengan gas isian argon dan etanol. Tetapi gas halogen juga mempunyai sifat negatif selain beracun juga sangat reaktif sehingga dalam pembuatan detektor Geiger-Mueller perlu dipilih bahan yang tahan terhadap sifat tersebut. Kesulitan lainnya karena tekanan gas $\mathrm{Br}$ yang sangat kecil $0,1-1 \%$ dari tekanan total gas isian detektor PRICE. $\mathrm{J}^{[8]}$, maka untuk memasukkan gas $\mathrm{Br}$ ke dalam tabung detektor perlu peralatan pengukur tekanan yang sangat teliti agar diperoleh perbandingan yang tepat antara gas Ar dengan gas $\mathrm{Br}$, sehingga perlu dilakukan penelitian lebih lanjut untuk mencapai hasil yang optimum.

\section{Pengujian Resolving Time Detektor Dengan Gas Isian Ar-Etanol dan $\mathrm{Ar}-\mathrm{Br}$}

Setelah diketahui panjang plateau, slope dan tegangan operasi detektor yang terbaik, dalam hal ini untuk gas isian Ar-etanol dicapai pada perbandingan 9:1, maka dilakukan pengujian waktu resolusi (T) dengan tegangan operasi yang dipasang pada tegangan tengah plateau yakni $1160 \mathrm{~V}$, sedang untuk gas isian $\mathrm{Ar}-\mathrm{Br}$ keadaan terbaik diperoleh pada perbandingan 100:1 pada tegangan operasi $540 \mathrm{~V}$. Untuk pengukuran resolving 
Pengaruh Tekanan Gas Isian Argon-Etanol dan Argon-Brom Terhadap Unjuk Kerja Detektor Geiger-Mueller (Sayono, BA. Tjipto Sujitno)

time dilakukan dengan metode pencacahan menggunakan dua sumber radioaktif yang sama. Dalam hal ini digunakan sumber radioaktif Cs-137, dengan aktivitas masing-masing $10 \mu \mathrm{Ci}$. Hasil pencacahan untuk menentukan resolving time detektor gas isian Ar-etanol dan Ar-Br disajikan pada Tabel 4.

Tabel 4. Data pencacahan untuk menentukan resolving time detektor Geiger-Mueller dengan gas isian Aretanol dan Ar-Br menggunakan sumber Cs-137.

\begin{tabular}{|c|c|c|c|c|}
\hline \multirow[t]{2}{*}{$\mathrm{HV}(\mathrm{V})$} & \multicolumn{4}{|c|}{ Hasil cacah Ar-etanol $9: 1$ dengan tekanan total $10 \mathrm{cmHg}$} \\
\hline & $\mathrm{N}_{1}(\mathrm{cpm})$ & $\mathrm{N}_{1-2}(\mathrm{cpm})$ & $\mathrm{N}_{2}(\mathrm{cpm})$ & $\mathrm{N}_{\mathrm{b}}(\mathrm{cpm})$ \\
\hline \multirow{5}{*}{1160} & 3235 & 6079 & 3125 & 134 \\
\hline & 3172 & 5953 & 3068 & 137 \\
\hline & 3164 & 6134 & 3142 & 132 \\
\hline & 3143 & 6035 & 3089 & 133 \\
\hline & 3246 & 6073 & 3165 & 135 \\
\hline \multirow[t]{2}{*}{ Rerata } & $3190 \pm 44$ & $6055 \pm 66$ & $3112 \pm 31$ & $134 \pm 2$ \\
\hline & \multicolumn{4}{|c|}{ Cacah integral $=76295$ cacah } \\
\hline \multirow{2}{*}{$\mathrm{HV}(\mathrm{V})$} & \multicolumn{4}{|c|}{ Hasil cacah $\mathrm{Ar}-\mathrm{Br} 100: 1$ dengan tekanan total $20 \mathrm{cmHg}$} \\
\hline & $\mathrm{N}_{1}(\mathrm{cpm})$ & $\mathrm{N}_{1-2}(\mathrm{cpm})$ & $\mathrm{N}_{2}(\mathrm{cpm})$ & $\mathrm{N}_{\mathrm{b}}(\mathrm{cpm})$ \\
\hline \multirow{5}{*}{540} & 2063 & 3652 & 1820 & 152 \\
\hline & 1917 & 3585 & 1833 & 149 \\
\hline & 1945 & 3644 & 1895 & 158 \\
\hline & 2078 & 3675 & 1921 & 153 \\
\hline & 2015 & 3745 & 1813 & 157 \\
\hline \multirow[t]{2}{*}{ Rerata } & $2004 \pm 29$ & $3660 \pm 52$ & $1856 \pm 47$ & $154 \pm 4$ \\
\hline & \multicolumn{4}{|c|}{ Cacah integral $=65926$ cacah } \\
\hline
\end{tabular}

Berdasarkan Tabel 4 maka resolving time dari detektor (T) dapat dihitung menggunakan persamaan ${ }^{[3]}$ ) $\tau=\frac{N_{1}+N_{2}-N_{1-2}-N_{b}}{\left(N_{1-2}\right)^{2}-\left(N_{1}\right)^{2}-\left(N_{2}\right)^{2}}$,

dengan $\quad N_{1}$ : jumlah cacah sumber 1 ,

$\mathrm{N}_{2}$ : jumlah cacah sumber 2 ,

$\mathrm{N}_{1-2}$ : jumlah cacah sumber 1 dan 2 ,

$\mathrm{N}_{\mathrm{b}}$ : jumlah cacah latar.

Resolving time detektor dengan gas isian Ar-etanol

$$
\tau=\frac{3190+3112-6055-134}{(6055)^{2}-(3190)^{2}-(3112)^{2}}=\frac{113}{(36663025)-(10176100)-(9684544)}=6,725 \mu
$$

detik.

Resolving time detektor dengan gas isian $\mathrm{Ar}-\mathrm{Br}$

$\tau=\frac{2004+1856-3660-154}{(3660)^{2}-(2004)^{2}-(1856)^{2}}=\frac{46}{(13395600)-(4016016)-(3444736)}=7,75 \mu$ detik.

\section{Menentukan Nilai Cacah Sebenarnya Detektor Geiger-Mueller Dengan Gas Ar-Etanol dan Ar-Br}

Detektor Geiger-Mueller selama digunakan untuk mencacah radiasi mengalami waktu mati (dead time) atau tidak respon terhadap radiasi yang datang sehingga diperlukan faktor koreksi untuk mengetahui nilai cacah yang sebenarnya $\left(\mathrm{N}_{\mathrm{sb}}\right)$. Data untuk menentukan nilai cacah yang sebenarnya $\left(\mathrm{N}_{\mathrm{sb}}\right)$ detektor Geiger-Mueller dengan gas isian Ar-etanol dan Ar-Br disajikan pada Tabel 5. 
Berdasarkan Tabel 5, untuk detektor dengan gas isian Ar-etanol diperoleh $\mathrm{N}$ tercacah $\left(\mathrm{N}_{\mathrm{t}}\right)$ sebesar 3212$136=3076 \mathrm{cpm}$, sedang untuk detektor dengan gas isian Ar-Br diperoleh $\mathrm{N}$ tercacah $\left(\mathrm{N}_{\mathrm{t}}\right)$ sebesar 1863-149= $1714 \mathrm{cpm}$. Faktor koreksi $\left(\mathrm{F}_{\mathrm{T}}\right)$ detektor Geiger-Mueller dapat ditentukan dengan menggunakan persamaan $F_{\tau}=1-\left(N_{t} \times \tau\right)$

dengan $\mathrm{F}_{\mathrm{T}}=$ faktor koreksi, $\mathrm{N}_{\mathrm{t}}=\mathrm{N}$ tercacah, $\mathrm{T}=$ resolving time.

Menghitung faktor koreksi detektor Gieger Mueller gas isian Ar-etanol

$F_{\tau}=1-\left(N_{t} \times \tau\right) \quad=1-\left(3076 \times 6,725 \times 10^{-6}\right)=0,98$.

Nilai cacah sebenarnya $\left(N_{s b}\right)$ dapat diketahui dengan persamaan $N_{s b}=\frac{N_{t}}{\left(1-N_{t} \times \tau\right)}$

$N_{s b}=\frac{3076}{\left(1-3076 \times 6,725 \times 10^{-6}\right)}=3139 \mathrm{cpm}$

Tabel 5. Data hasil pencacahan untuk nilai cacah yang sebenarnya dengan sumber Cs-137

\begin{tabular}{|c|c|c|}
\hline $\mathrm{HV}(\mathrm{V})$ & \multicolumn{2}{|c|}{ Hasil pencacahan Ar-etanol 9:1 dengan tekanan total $10 \mathrm{cmHc}$} \\
\hline \multirow{6}{*}{1160} & $\mathrm{~N}$ tercacah (cpm) & Cacah latar (cpm) \\
\hline & 3136 & 135 \\
\hline & 3258 & 138 \\
\hline & 3226 & 134 \\
\hline & 3176 & 135 \\
\hline & 3265 & 137 \\
\hline \multirow{2}{*}{ Rata-rata } & $3212 \pm 49$ & $136 \pm 2$ \\
\hline & \multicolumn{2}{|c|}{ Cacah integral $=21583$ cacah } \\
\hline HV (volt) & \multicolumn{2}{|c|}{ Hasil pencacahan $\mathrm{Ar}-\mathrm{Br}$ 100:1 dengan tekanan total $20 \mathrm{cmHg}$} \\
\hline \multirow{6}{*}{540} & $\mathrm{~N}$ tercacah (cpm) & Cacah latar (cpm) \\
\hline & 1865 & 145 \\
\hline & 1798 & 151 \\
\hline & 1854 & 149 \\
\hline & 1920 & 152 \\
\hline & 1879 & 148 \\
\hline \multirow[t]{2}{*}{ Rata-rata } & $1863 \pm 39$ & $149 \pm 2$ \\
\hline & \multicolumn{2}{|c|}{ Cacah integral = 15836 cacah } \\
\hline
\end{tabular}

Menghitung faktor koreksi detektor Gieger Mueller gas isian $\mathrm{Ar}-\mathrm{Br}$

$F_{\tau}=1-\left(N_{t} \times \tau\right)=1-\left(1714 \times 7,75 \times 10^{-6}\right)=0,988$.

Nilai cacah sebenarnya $\left(\mathrm{N}_{\mathrm{sb}}\right)$ untuk detektor Gieger Mueller gas isian Ar-Br diperoleh

$$
N_{s b}=\frac{1714}{\left(1-1714 \times 7,75 \times 10^{-6}\right)}=1737 \mathrm{cpm} \text {. }
$$

Dari hasil cacah sebenarnya $\left(\mathrm{N}_{\mathrm{sb}}\right)$ hasil perhitungan untuk detektor Geiger-Mueller yang diisi gas Ar-etanol diperoleh nilai $3139 \mathrm{cpm}$, sedang saat pencacahan $\left(\mathrm{N}_{\mathrm{t}}\right)$ diperoleh nilai $3076 \mathrm{cpm}$ sehingga ada perbedaan antara nilai cacah sebenarnya $\left(\mathrm{N}_{\mathrm{sb}}\right)$ dengan hasil yang tercacah oleh detektor $\left(\mathrm{N}_{\mathrm{t}}\right)$ sebesar 3139-3076 $=63 \mathrm{cpm}$. Nilai cacah sebenarnya $\left(\mathrm{N}_{\mathrm{sb}}\right)$ lebih banyak bila dibanding dengan nilai yang tercacah oleh detektor. Demikian juga pada detektor Geiger-Mueller dengan gas isian Ar-Br diperoleh tercacah oleh detektor $\left(\mathrm{N}_{\mathrm{t}}\right)$ sebesar $1714 \mathrm{cpm}$, dan nilai cacah sebenarnya $\left(\mathrm{N}_{\mathrm{sb}}\right)$ sebesar $1737 \mathrm{cpm}$, sehingga terdapat selisih sebesar 1737-1714 =23 cpm. Hal ini terjadi karena detektor Geiger-Mueller mempunyai resolving time yakni sebesar $\mathrm{T}=6,725 \mu$ detik untuk Aretanol dan $\mathrm{T}=7,75 \mu$ detik untuk $\mathrm{Ar}$-Br sehingga pada waktu tersebut detektor tidak tanggap/respon terhadap radiasi yang datang mengenai detektor. Hal ini sesuai pendapat WISNU ARYA W $\cdot^{[3]}$, yang mengatakan apabila ada dua zarah radiasi yang masuk ke dalam detektor berurutan dalam waktu yang berdekatan, maka akibat 
peristiwa avalanche ion dari zarah radiasi pertama akan menyebabkan detektor tidak respon beberapa saat sehingga tidak dapat mencacat adanya zarah radiasi yang datang kemudian.

Semakin kecil nilai resolving time (waktu pemulihan yang diperlukan oleh detektor dapat merespon radiasi yang datang berikutnya) berarti detektor Geiger-Mueller akan semakin sensitif/peka terhadap radiasi yang datang, dengan demikian perbedaan nilai tercacah sebelum dikoreksi dibandingkan dengan nilai cacah sebenarnya setelah dikoreksi akan semakin kecil pula. Adanya waktu mati pada detektor Geiger-Mueller merupakan suatu kelemahan dari detektor tersebut, sehingga detektor ini tidak cocok untuk mengukur sumber radiasi yang mempunyai aktivitas tinggi, karena sumber radiasi yang memiliki aktivitas tinggi akan memancarkan intensitas radiasi yang semakin besar pula dan adanya waktu mati pada detektor Geiger-Mueller berarti akan banyak intensitas radiasi yang tidak terdeteksi oleh detektor

\section{Umur Detektor Geiger-Mueller dengan Gas Isian Ar-Etanol dan Ar-Br}

Umur detektor Geiger-Mueller berbanding lurus dengan jumlah cacah yang dihasilkan oleh detektor tersebut. Pada penelitian ini umur detektor belum dapat diketahui karena selama melakukan karakterisasi detektor masih memiliki plateau yang panjang dan bentuk pulsanya belum mengalami discharge. Jumlah cacah yang dihasilkan detektor dengan gas isian Ar-etanol sebanyak 3,105 $\times 10^{5}$ cacah, sedang jumlah cacah yang dihasilkan detektor dengan gas isian $\mathrm{Ar}-\mathrm{Br}$ adalah $1,102 \times 10^{7}$ cacah.

\section{KESIMPULAN}

Dari hasil penelitian pengaruh tekanan gas isian argon-etanol dan argon-brom terhadap unjuk kerja pada detektor Geiger-Mueller dapat disimpulkan sebagai berikut :

Untuk gas etanol sebagai gas pemadam pada perbandingan Ar-etanol sebesar 9:1 pada tekanan 10 $\mathrm{cmHg}$ diperoleh karakteristik terbaik panjang plateau $180 \mathrm{~V}$, slope $9,60 \% / 100 \mathrm{~V}$, tegangan operasi $1160 \mathrm{~V}$ dan resolving time $\mathrm{T}=6,725 \mu$ detik.

Untuk gas halogen $(\mathrm{Br})$ sebagai pemadam pada perbandingan $100: 1$ pada tekanan $20 \mathrm{cmHg}$ diperoleh karakteristik terbaik panjang plateau $100 \mathrm{~V}$, slope $42,32 \% / 100 \mathrm{~V}$, tegangan operasi $540 \mathrm{~V}$ dan resolving time T $=7,75 \mu$ detik

Pada penelitian ini umur detektor belum dapat diketahui karena selama melakukan karakterisasi detektor masih memiliki plateau yang panjang dan bentuk pulsanya belum mengalami discharge. Jumlah cacah yang dihasilkan detektor sementara untuk gas isian Ar-etanol sebesar 3,105 ×106 cacah, sedang untuk $\mathrm{Ar}$-Br sebesar $1,102 \times 10^{7}$ cacah.

\section{UCAPAN TERIMA KASIH}

Dengan selesainya penelitian ini kami mengucapkan banyak terima kasih kepada Bapak Prof. Dr. Pramudita Anggraita, Prof. Drs. Sudjatmoko, SU., Prof. Darsono, M.Sc., Irianto, A.Md., Sumarmo dan seluruh staf kelompok Aplikasi Akselerator atas segala bantuan yang telah diberikan.

\section{DAFTAR PUSTAKA}

1. SURAHKMAN, SAYONO, "Pembuatan Detektor Geiger-Mueller Tipe Jendela Samping Dengan Gas Isian Argon -Etanol", Prosiding Seminar Nasional V Sumber Daya Manusia Teknologi Nuklir, STTN-BATAN, Yogyakarta, 5 November (2009).

2. AGUS SANTOSO, "Pembuatan Detektor Geiger-Mueller Tipe Jendela Samping Dengan Gas Isian Neon dan Chlor", Prosiding Pertemuan dan Presentasi Ilmiah Penelitian dasar Ilmu Pengetahuan dan Teknologi Nuklir, PPNY-BATAN, Yogyakarta, 21-22 Maret (1990), hal 370-374.

3. WISNU ARYA W., Teknologi Nuklir, Proteksi Radiasi dan Aplikasinya, Penerbit Andi, Yogyakarta (2007) 209-121.

4. AGUS SANTOSO, "Pengaruh Tekanan Gas Isian Terhadap Karakteristik Detektor Geiger-Mueller dengan gas Isian Neon-Brom", Prosiding Pertemuan dan Presentasi IImiah Penelitian dasar IImu Pengetahuan dan Teknologi Nuklir, PPNY-BATAN, Yogyakarta, 26-28 April (1994), hal 27-35.

5. E. FEYVES AND O. HAIMAN, The Phycical Principles of Nuclear Radiation Measurement, Academisi Kiado, Budapest (1969) 219-235. 
6. NICHOLAS TSOULFANIDIS, Measurement and Detection of Radiation, University of Missouri-Rolla, New York USA, (1983) 169-177.PETER SOEDOJO, Azas-Azas IImu Fisika Jilid 4 Fisika Modern, FMIPA-UGM, Gadjah Mada Press Yogyakarta, Edisi 1 (2001) 226-232.

7. ROLF MICHEL, Radiation Measurement Method, A part of Nuclear Analytical Techniques, ZSR, Leibniz Univitet, Hanover (2008) 4-5.

8. PRICE, W.J., Nuclear Radiation Detection, Second Edition, Mc Graw-Hill Book Company, New York (1964) 1-28, 41-49,123-126.

9. KNOLL, GLENN F., Radiation Detection and Measurement, John Wiley \& Sons, Inc, New York (2000) 41-42.

10. AGUS SANTOSO, BA. TJIPTO SUJITNO, SAYONO, MUDJIONO, SUMARMO, Alat Detektor Radiasi dengan Perakitan Elektroda Menggunakan sistem Pengelasan Gelas dengan Logam, patent No. ID 0000667 S, SK Ditjen HKI No.H3.HC.04.02.-2767/2006.

11. HARSHAW, Nuclear Detectors and Systems Halogen Quenched Geiger-Mueller Tubes, Catalog. Crystal \& Electronic Departement, Solon, Ohio, USA. (1998) 2-3. 